\title{
CBNAAT Positivity in Sputum of Tuberculosis Patients with HIV
}

\author{
Hariom Gupta1, Ravi Prakash Pandey², Manoj Kumar Prajapati³, Manoj Indurkar4 \\ 1Department of Medicine, Shyam Shah Medical College, Rewa, Madhya Pradesh, India. ${ }^{2}$ Department of Medicine, \\ Shyam Shah Medical College, Rewa, Madhya Pradesh, India. ${ }^{3}$ Department of Medicine, Shyam Shah Medical College, \\ Rewa, Madhya Pradesh, India. ${ }^{4}$ Department of Medicine, Shyam Shah Medical College, Rewa, Madhya Pradesh, India.
}

\section{ABSTRACT}

\section{BACKGROUND}

Tuberculosis is one of the commonest opportunistic infections in HIV positive patients. Sputum smear microscopy takes a minimum of 2 days for detection of PTB. In December 2010, the WHO recommended use of CBNAAT in detection of pulmonary TB along with Rifampicin resistance. It takes $<2$ hours. We wanted to evaluate the CBNAAT positivity in sputum of tuberculosis patients by correlating with sputum smear microscopy and detection of rifampicin resistance.

\section{METHODS}

This is an observational study conducted among 160 patients with age $>15$ years. All HIV positive patients with sputum positive or sputum negative for PTB were included in the study. All patients with extrapulmonary tuberculosis were excluded from the study.

\section{RESULTS}

Middle aged 26-45 years (68.12\%) old individuals are the most commonly affected especially the rural population (84.66\%). The population which is more commonly affected is the low education status individuals (primary and high school, 35\% and $33.75 \%$ respectively); but, among the females, uneducated groups are more commonly affected. Transmission of disease is found to be highest due to sexual contact $(73.12 \%)$ in which males are more prone $(71.55 \%)$ and least with I.V. drug abusers (4.38\%). By comparing CBNAAT and Sputum AFB positivity, CBNAAT positivity ( $45 \%$ ) is found to be more than sputum smear microscopy (15\%); it means, CBNAAT positive and sputum AFB negative cases are $31.2 \%$, while CBNAAT negative and sputum AFB positive cases are minimum (1.2\%), showing false negativity of sputum smear microscopy and high sensitivity and specificity of CBNAAT. Maximum cases with CD4 count $>200$, are both CBNAAT and sputum AFB negative and least cases are CBNAAT negative and sputum AFB positive with regard to CD4 count. It is found that $25 \%$ were resistant for rifampicin. It helps in screening of MDR patients.

\section{CONCLUSIONS}

CBNAAT helps in the early detection of tuberculosis and it takes less than 2 hours for this. CBNAAT is more sensitive for detection of tuberculosis in HIV positive cases in comparison to sputum smear microscopy. It reduces the false negativity rates. CBNAAT detects drug resistance mainly rifampicin and helps in screening of MDR.

\section{KEY WORDS}

CBNAAT, HIV, Tuberculosis, Sputum, AFB

\author{
Corresponding Author: \\ Dr. Ravi Prakash Pandey, \\ F-18, Doctor's Colony, \\ Medical College Campus, \\ Rewa-486001, \\ E-mail: drraviprakashpandey@gmail.com
}

DOI: $10.14260 /$ jemds/2019/815

Financial or Other Competing Interests: None.

How to Cite This Article:

Gupta H, Pandey RP, Prajapati MK, et al. CBNAAT positivity in sputum of tuberculosis patients with HIV. J. Evolution Med. Dent. Sci. 2019;8(50):3764-3768, DOI: $10.14260 /$ jemds/2019/815

Submission 14-10-2019,

Peer Review 27-11-2019,

Acceptance 03-12-2019,

Published 16-12-2019. 


\section{BACKGROUND}

Tuberculosis and HIV have been closely linked since the emergence of AIDS. HIV infection has contributed to a significant increase in the worldwide incidence of tuberculosis. ${ }^{1,2}$ By producing a progressive decline in cellmediated immunity, HIV alters the pathogenesis of tuberculosis, greatly increasing the risk of developing disease in co-infected individuals and leading to more frequent extra pulmonary involvement and atypical radiographic manifestations. Although HIV-related tuberculosis is both treatable and preventable, incidence rates continue to climb in developing nations where HIV infection and tuberculosis are endemic, and resources are limited. Worldwide, tuberculosis is the most common opportunistic infection affecting HIV-sero-positive individuals, ${ }^{3}$ and it is the most common cause of death in patients with AIDS. 4

Cartridge based nucleic acid amplification test (CBNAAT), specific for Mycobacterium tuberculosis, has been recently introduced for detection of TB. It has an added advantage of detecting rifampicin resistance as it targets the rpoB gene of mycobacteria, which is the critical gene associated with rifampicin resistance. The test is highly specific and does not give cross reactions with any other bacterial species including a comprehensive panel of mycobacteria thereby excluding non-tubercular mycobacteria. In a study, the overall sensitivity, specificity, positive predictive value and negative predictive value of CBNAAT test (Gene Xpert MTB/RIF assay) were found to be $98.6 \%, 100 \%, 100 \%$ and $93.8 \%$, respectively. ${ }^{5}$

\section{METHODS}

The present study was an observational study undertaken in S.S. Medical College and Sanjay Gandhi Memorial Hospital, Rewa, in the Department of Medicine with proper written and informed consent. Sample size was taken according to number of new admissions and follow up cases of TB and HIV. The study group included a total number of 160 radiologically, bacteriologically and clinically confirmed patients of tuberculosis either admitted in wards or attending the outpatient department or ART center during April 2018 to June 2019, who were HIV positive previously treated or newly detected or follow up patients.

\section{Inclusion Criteria}

1. All radiologically and / or bacteriologically or clinically confirmed patients of pulmonary tuberculosis with HIV positive status aged $\geq 15$ years.

2. All old or follow up or new HIV positive patients who were also positive for pulmonary tuberculosis.

3. Patients who gave written informed consent. In patients $<18$ yrs. consent was obtained from their parents or guardians.

\section{Exclusion Criteria}

1. HIV positive with Pulmonary tuberculosis patients $<15$ years of age.

2. Extrapulmonary tuberculosis patients.

3. Patients who refused to give consent.
4. HIV patients with old pulmonary tuberculosis not on ATT.

\section{Investigations for Diagnosis}

Apart from clinical manifestation and history, the diagnosis of PTB was based on (1) CBNAAT (2) Sputum AFB (3) X-Ray Chest (P.A. View)

\section{RESULTS}

This study was conducted on 160 PTB/HIV patients. Out of 160 PTB/HIV patients, 116 (72.5\%) were males and 44 (27.5\%) were females. The mean age in this study was 38.01 yrs. and the sex ratio was 2.63:1 Middle aged 26-45 years (68.12\%) individual were most commonly affected especially the rural population (84.66\%). The population more commonly affected was the low education status individuals (Primary and high school, 35\% and 33.75\% respectively) but among the females, uneducated groups $(54.54 \%$ of total females) were more commonly affected. Maximum no. of cases were labourers 60 (37.5\%), followed by housewives 35 (21, $87 \%$ ), followed by truck driver $25(15.65 \%)$. The transmission of disease was found to be highest due to sexual contact $(73.12 \%)$ in which males were more prone $(71.55 \%)$ and least with I.V. drug abusers (4.38\%).Out of 24 sputum smear positive cases higher no. of sputum smear positive among in CD4 above 200 i.e. 19 (79.16\%) and lower among CD4 below 200 i.e. 5 (20.83\%).

Among the CBNAAT positive cases who were resistant to Rifampicin, maximum 12 (67\%) of them were previously treated cases followed by 6(33\%) were new cases. By comparing CBNAAT and Sputum AFB positivity, CBNAAT positivity(45\%) was found more than sputum smear microscopy(15\%).CBNAAT positive and sputum AFB negative cases were $31.2 \%$, while CBNAAT negative and sputum positive cases were minimum (1.2\%), showing false negativity of sputum smear microscopy and high sensitivity and specificity of CBNAAT. Maximum cases with CD4 count $>200$, are both CBNAAT and Sputum AFB Negative and least cases were CBNAAT Negative and sputum positive in respect to CD4 count. It is found that $25 \%$ were resistant to rifampicin. It helps in screening of MDR patients.

\begin{tabular}{|c|c|c|c|c|c|c|}
\hline \multirow{3}{*}{$\begin{array}{l}\text { Sl. } \\
\text { No. }\end{array}$} & \multirow{3}{*}{$\begin{array}{c}\text { Route of } \\
\text { Transmission }\end{array}$} & \multicolumn{4}{|c|}{ Number of Cases } & \multirow{3}{*}{ Total } \\
\hline & & \multicolumn{2}{|c|}{ Male } & \multicolumn{2}{|c|}{ Female } & \\
\hline & & & $\%$ & & $\%$ & \\
\hline 1. & Sexual & 83 & $71.55 \%$ & 34 & $77.27 \%$ & $117(73.12 \%)$ \\
\hline 2. & Blood and its products & 26 & $22.42 \%$ & 10 & $22.73 \%$ & $36(22.5 \%)$ \\
\hline 3. & IV drug users & 7 & $6.03 \%$ & 0 & $0 \%$ & $7(4.38 \%)$ \\
\hline & Total & 116 & $100 \%$ & 44 & $100 \%$ & $160(100 \%)$ \\
\hline
\end{tabular}

\begin{tabular}{|c|c|c|}
\hline Correlation & Numbers & $\mathrm{CD} 4=\frac{\leq 200}{>200}$ \\
\hline Both CBNAAT and Sputum AFB Positive & $22(13.75 \%)$ & $\frac{4}{18}$ \\
\hline CBNAAT Positive and Sputum AFB Negative & $50(31.25 \%)$ & $\frac{25}{25}$ \\
\hline CBNAAT Negative and Sputum AFB Positive & $2(1.25 \%)$ & $\frac{1}{1}$ \\
\hline Both CBNAAT and Sputum AFB Negative & $86(53.75 \%)$ & $\frac{38}{48}$ \\
\hline Total & $160(100 \%)$ & 160 \\
\hline
\end{tabular}




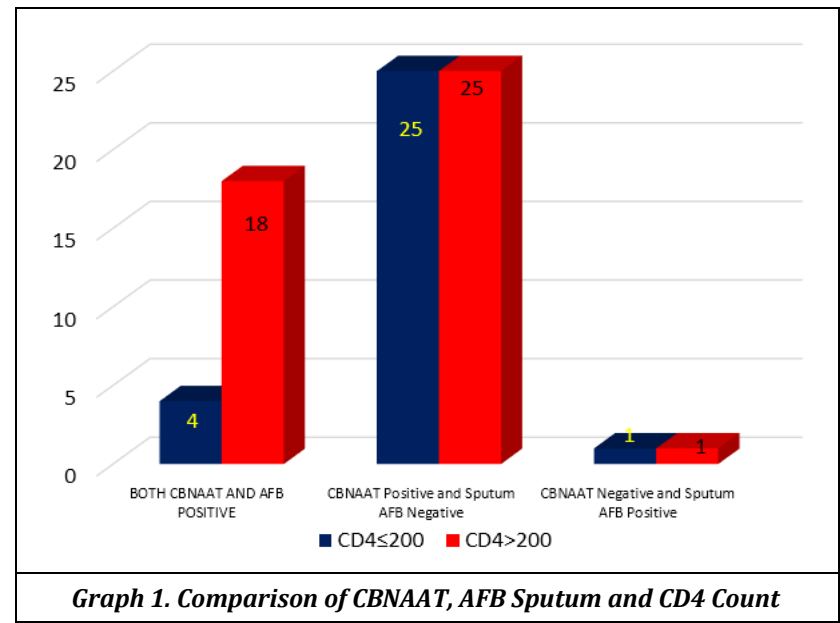

\begin{tabular}{|c|c|c|}
\hline & CBNAAT Positive Patients & $\%$ \\
\hline Rifampicin Sensitive & 54 & $75 \%$ \\
\hline Rifampicin resistance & 18 & $25 \%$ \\
\hline Total & 72 & $100 \%$ \\
\hline
\end{tabular}

Table 3. Rifampicin Resistance among CBNAAT Positive Patients

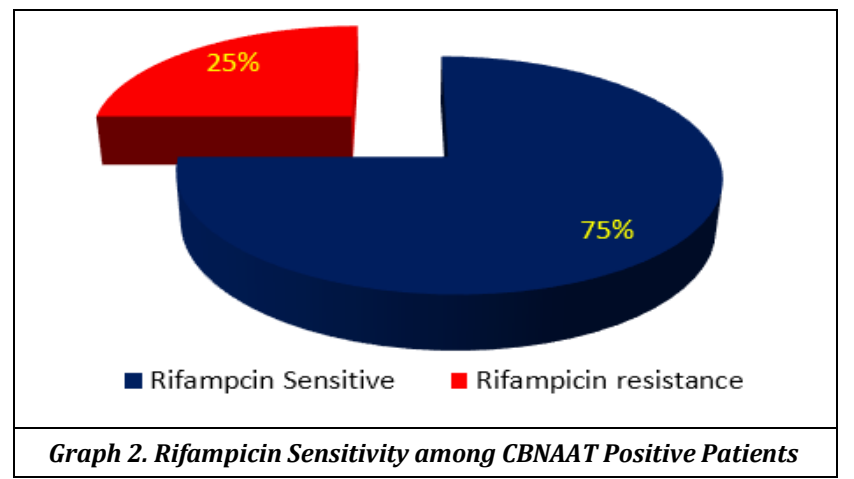

\begin{tabular}{|c|c|c|c|}
\hline Type of Case & $\begin{array}{c}\text { Positive } \\
\text { CBNAAT } \\
\text { Cases } \\
\text { Resistant to } \\
\text { (Rifampicin) }\end{array}$ & $\begin{array}{c}\text { Positive } \\
\text { CBNAAT Cases } \\
\text { Sensitive to } \\
\text { (Rifampicin) }\end{array}$ & Total \\
\hline Previously treated cases & $12(67 \%)$ & $32(59 \%)$ & 44 \\
\hline New & $6(33 \%)$ & $22(41 \%)$ & 28 \\
\hline Table 4. Comparing Rifampicin Resistance with CBNAAT Positivity \\
and Previously Treated Cases \\
\hline
\end{tabular}

\begin{tabular}{|c|c|c|c|c|c|}
\hline Study & $\begin{array}{c}\text { Sample } \\
\text { Size }\end{array}$ & $\begin{array}{c}\text { Positive for } \\
\text { Tuberculosis }\end{array}$ & $\begin{array}{c}\text { AFB } \\
\text { Positive }\end{array}$ & $\begin{array}{c}\text { CBNAAT } \\
\text { Positive }\end{array}$ & $\begin{array}{c}\text { Resistant } \\
\text { Cases }\end{array}$ \\
\hline Present Study & 160 & $74(46.25 \%)$ & $24(15 \%)$ & $72(45 \%)$ & $18(11.25 \%)$ \\
\hline D Pragati Rao et al & 231 & 59 & $14(6.06 \%)$ & $59(25.54 \%)$ & $8(3.4 \%)$ \\
\hline $\begin{array}{c}\text { Deepak Bansal } \\
\text { et al }\end{array}$ & 604 & $91(15.06 \%)$ & - & $91(15.06 \%)$ & $6(0.99 \%)$ \\
\hline $\begin{array}{c}\text { Prem Prakash } \\
\text { Gupta et al }{ }^{6}\end{array}$ & 30 & $25(83.33 \%)$ & $8(26.66 \%)$ & $17(56.66 \%)$ & $2(6.66 \%)$ \\
\hline R Dewan et al & 100 & $40(40 \%)$ & $11(11 \%)$ & $40(40 \%)$ & $9(9 \%)$ \\
\hline
\end{tabular}

\section{DISCUSSION}

Tuberculosis seen among HIV infected individual is the most common opportunistic infection 7 . The clinical radiological and bacteriological manifestation vary with the level of immunosuppression and CD4 count ${ }^{8,9}$.In present study, most of the HIV with pulmonary TB cases were in the age group of 26-45 years $(68.12 \%)$. Mean age was 38.01 yr. It can be comparable with R Dewan et al (June 2015)..$^{10}$ The mean age of the study population was $35 \pm 9$ years. Most patients (69\%) were in the age group of 20 to 40 years. P Giriet al (June 2013) ${ }^{11}$ found $58.10 \%$ PTB/HIV patients were in 21-40 years age group. In Hussain $\mathrm{T}$ et al (2006) ${ }^{12}$ it was $90.9 \%$. In present study, among 160 cases, 116 patients $(72.5 \%)$ were male showing dominancy. Male to female ratio was found 2.63:1. By comparing with R Dewan et al (June 2015) ${ }^{10}$ it was found that majority (76\%) of the patients in the study were men. Pratima Gupta et al (2006) ${ }^{13}$ found $71.42 \%$ were male. Ghiya R et al (2009) ${ }^{14}$ observed males were more affected than females. Male to female ratio 6:4. Neeraj Raizadaet al (2008) ${ }^{15}$ found 69.4\% PTB in HIV positive patient were males Lissane Seifuet al $(2005)^{16}$ studied total 925 cases with sex ratio of male: female is 1.1:1.

In the present study, among 160 cases, $60(37.5 \%)$ were labourers and farmers, housewives 35 (21.87\%), truck drivers 25 (15.65\%). In Anand K Patel et al (June 2011) ${ }^{17}$ they observed that $30 \%$ farmer, $22 \%$ labourers and $16 \%$ drivers were suffered from coinfection. In Shrikant Reddy et al (July 2013) ${ }^{18} 45.4 \%$ labourers, $36.4 \%$ drivers and $9.09 \%$ farmers were affected. P Giriet al (June 2013) ${ }^{10]}$ they observed that $29.65 \%$ farmer, $42.44 \%$ labourers and $15.11 \%$ drivers were affected. In the present study transmission of the disease mostly occurs by a sexual route $(72.22 \%)$, blood and its products (22.22\%) and least with IVD users (5.60\%). Pratima Gupta et al (2006) ${ }^{12}$ who found transmission of HIV in PTB patients was mainly through heterosexual route $(66.67 \%)$. Ghiyaet al (2009), ${ }^{13}$ heterosexual route (65\%), through blood transfusion (13.8\%). Shrikant Reddy et al (July 2013) ${ }^{17}$ found that transmission through heterosexual route was $84.6 \%$.

In the present study out of 72 CBNAAT positive patients, $43(59.73 \%)$ had CD4 count $>200$ and $29(40.27 \%)$ had CD 4 count $<200$. Similar study has done by R Dewanet al $(2015)^{9}$ they studied that CBNAAT positivity was seen across all ranges CD4 counts and there was no statistically significant difference between CD4 count of CBNAAT positive and CBNAAT negative patients. N Talikoti et al (2019) also found the same. In the present study among 160 cases, CBNAAT positivity was $72(45 \%)$ and sputum smear positivity was 24(15\%).R Dewanetal (2015). ${ }^{10}$ They studied that 11 patients out of $100(11 \%)$ were positive by sputum microscopy for AFB and $40 \%$ were positive by CBNAAT. Thus, tuberculosis detection rate increased by more than three times using CBNAAT. N Talikoti et al (2019) ${ }^{19}$ studied that out of 100 cases who were HIV seropositive 11 newly diagnosed HIV cases, presented with features suggestive of pulmonary tuberculosis (All are Newly diagnosed pulmonary TB).

In present study among 160 cases, correlation between CBNAAT negativity and sputum positivity was only $1.25 \%$ (2 cases), showing approx. $100 \%$ sensitivity of CBNAAT. Both CBNAAT and sputum smear positivity were 22(13.5\%). CBNAAT positivity and sputum smear microscopy negativity were 50 (31.25\%), showing the large number of false negativity of sputum smear microscopy and specifying the CBNAAT sensitivity and specificity. N Talikoti et al (2019). ${ }^{18}$ They studied 31 subjects with CBNAAT positivity, $41.9 \%$ were positive in Sputum AFB, 58.1\% were negative in Sputum AFB (false negative). D. Pragati Rao, K. Lakshmi Sowjanya et al (2016) ${ }^{19}$ Out of 231 HIV positive patients, 59 cases (25.54\%) had tuberculosis. Sputum smear for AFB negative and Gene Xpert positive were $45(76.27 \%) .8(13.55 \%)$ cases were Rifampicin resistance and 51 (86.44\%) were sensitive out of all tuberculosis patients. Deepak Bansal, Sanjay Avashia, 
Mitesh Karothiya ${ }^{20} 2015$ studied 3033 pulmonary specimens were included in the study undergoing Gene Xpert; out of which 604 specimen were from HIV positive patients. In 85 (14.07\%) HIV positive patients (Out of 604) MTB was detected and RIF was sensitive (14.07\%). In 06 (0.99\%) HIV positive patients, MTB was detected and RIF resistance was found.

In present study out of 72 CBNAAT positive cases, 18 (25\%) cases were resistant to rifampicin and 54(75\%) were sensitive to rifampicin. R dewan et al (2015) ${ }^{9}$ they studied that CBNAAT diagnosed $10(25 \%)$ cases of rifampicin resistance among the 40 Mycobacterium tuberculosis positive cases. On LPA, all these were confirmed to be resistant to rifampicin. CBNAAT had $100 \%$ specificity for detection of rifampicin resistance. Both these results were available within 2 hours. Theron $\mathrm{G}$ et al (2011) ${ }^{21}$ studied on drug resistance have shown that rifampicin resistance is seldom detected alone and $90 \%$ of rifampicin resistant patients turn out to be MDR-TB. they studied that $9 / 10$ rifampicin resistant samples also demonstrated resistance to isoniazid. Hence CBNAAT can be a useful test for screening for MDR-TB. In our study among the CBNAAT positive cases who were resistant to Rifampicin, maximum $12(67 \%)$ of them, were previously treated cases followed by $6(33 \%)$ were new cases, showing resistance was more common with previously treated patients. There are mixed type reports from different studies from different parts of world.

Some says pattern of resistance to rifampicin is low among newly diagnosed cases, some says that it is common with previously treated patients. Mahendra Kumar et al (2016) ${ }^{22}$ studied that out of 200 study population, Mycobacterium tuberculosis was detected in 159 (79.5\%) cases by CBNAAT. The overall prevalence of rifampicin resistance among previously treated pulmonary tuberculosis was $22.64 \%$ (36/159). The prevalence of rifampicin resistance among sputum positive previously treated pulmonary tuberculosis was $25.21 \%$ (31/123) whereas the prevalence of rifampicin resistance among previously treated sputum negative pulmonary tuberculosis was $13.8 \%(5 / 36)$.

\section{CONCLUSIONS}

CBNAAT helps in the early detection of tuberculosis and it takes less than 2 hours for this. CBNAAT was more sensitive for detecting tuberculosis in HIV positive cases in comparison to sputum smear microscopy. It reduces the false negative rates. CBNAAT detects drug resistance mainly rifampicin and helps in screening of MDR. Other than this, we have to provide proper knowledge about the TB/HIV, safety measures, and treatment regarding the disease, especially to $25-45$ years age group with emphasis on housewives who are more prone to the disease.

\section{REFERENCES}

[1] Divisions of HIV/AIDS Prevention (2003). HIV and Its Transmission. Centers for Disease Control \& Prevention. Archived from the original on February 4, 2005. Retrieved 2006-05-23.
[2] San Francisco AIDS Foundation (2006-04-14). How HIV is spread. Retrieved 2006-05-23.

[3] AIDS Control and Prevention (AIDSCAP) Project of Family Health Internal, the Francois-Xavier Bagnoud Center for Public Health and Human Rights of the Harvard School of Public Health, UNAIDS. The Status and Trends of the Global HIV/AIDS Pandemic. Final Report July 5-6, 1996.

[4] Raviglione MC, Narain JP, Kochi A. HIV-associated tuberculosis in developing countries: clinical features, diagnosis and treatment. Bull WHO 1992;70(4):515-26.

[5] Pandey P, Pant ND, Rijal KR, et al. Diagnostic accuracy of GeneXpert MTB/RIF assay in comparison to conventional drug susceptibility testing method for the diagnosis of multidrug-resistant tuberculosis. PLoS One 2017;12(1):e0169798.

[6] Gupta PP, Mynalli AB, Yadav A. Diagnostic role of cartridge based nucleic acid amplification test in diagnosing tuberculosis in patients co-infected with human immunodeficiency virus. JMSCR 2017;5(5):21841-8.

[7] Berry N, Jenkins A, Martin J, et al. Mitochondrial DNA and retroviral RNA analyses of archival oral polio vaccine (OPV CHAT) materials: evidence of macaque nuclear sequences confirms substrate identity. Vaccine 2005;23(14):1639-48.

[8] UNAIDS, WHO (December 2007). 2007 AIDS epidemic update (PDF). Retrieved 2008-03-12.

http://data.unaids.org/pub/FactSheet/2009/20091124 _FS_global_en.pdf

[9] Gao F, Bailes E, Robertson DL, et al. Origin of HIV-1 in the Chimpanzee Pan troglody-test roglodytes. Nature 1999;397(6718):436-41.

[10] Dewan R, Anuradha S, Khanna A, et al. Role of cartridgebased nucleic acid amplification test (CBNAAT) for early diagnosis of pulmonary tuberculosis in HIV. J Indian Acad Clin Med 2015;16(2):114-7.

[11] Giri PA, Deshpande JD, Phalke DB. Prevalence of pulmonary tuberculosis among HIV positive patients attending antiretroviral therapy clinic. N Am J Med Sci 2013;5(6):367-70.

[12] Hussain T, Sinha S, Kulshreshtha KK, et al. Seroprevalence of HIV infection among tuberculosis patients in Agra, India-a hospital-based study. Tuberculosis (Edinb) 2006;86(1):54-9.

[13] Gupta P, Rawat J, Sindhwani G, et al. HIV sero-prevalence and tuberculosis in Uttaranchal. Indian $\mathrm{J}$ Tuberc 2006;53:96-100.

[14] Ghiya R, Naik E, Casanas B, et al. Clinico-epidemiological profile of HIV - TB coinfected patients in Vadodara, Gujarat. Indian J Sex Transm Dis \& AIDS 2009;30(1):1015.

[15] Raizada N, Chauhan LS, Khera A, et al. HIV seroprevalence among tuberculosis patients in India, 20062007. PLoS One 2008;3(8):e2970.

[16] Seifu L. Socio-demographic and clinical profile of AIDS patients in Jimma referral hospital, Southwest Ethiopia. Ethiopian Journal of Health Development 2005;18(3):203-7.

[17] Patel AK, Thakrar SJ, Ghanchi FD. Clinical and laboratory profile of patients with TB/HIV co-infection: a case series of 50 patients. Lung India 2011;28(2):93-6. 
[18] Bogle SR, Gouda N, Sharma VK, et al. Study of seroprevalence of HIV among tuberculosis patients and clinico-radiological implications of dual infections. Journal of Evolution of Medical and Dental Sciences 2013;2(27):4966-73.

[19] Rao DP, Sowjanya KL. Role of CBNAAT in rapid detection of Mycobacterium tuberculosis in PLHIV in a highly prevalent state. Journal of Evidence Based Medicine and Healthcare 2016;3(38):1896-8.

[20] Bansal D, Avashia S, Karothiya M. A study of gene xpert in screening of sputum in HIV positive patients presenting to tertiary care centre. National Journal of Community Medicine 2016;7(8):657-60.

[21] Theron G, Peter J, van Zyl-Smit R, et al. Evaluation of the Xpert MTB/RIF assay for the diagnosis of pulmonary tuberculosis in a high HIV prevalence setting. American Journal of Respiratory and Critical Care Medicine 2011;184(1):132-40.

[22] Kumar M, Datta A, Kumar H. A study on prevalence of rifampicin resistance by Gene Xpert with clinicoradiological correlation in previously treated pulmonary tuberculosis patients. Int J Res Med 2016;5(2):52-6. 